\title{
A HERMENÊUTICA COMO POSSIBILIDADE METODOLÓGICA À PESQUISA EM EDUCAÇÃO
}

\section{LA HERMENÉUTICA COMO POSIBILIDAD METODOLÓGICA DE LA INVESTIGACIÓN EN EDUCACIÓN}

\author{
HERMENEUTICS AS A METHODOLOGICAL POSSIBILITY TO RESEARCH IN \\ EDUCATION
}

\author{
Pilar de Moraes SIDI ${ }^{1}$ \\ Elaine $\mathrm{CONTE}^{2}$
}

\begin{abstract}
RESUMO: O objetivo deste texto é problematizar e apontar caminhos para a utilização da hermenêutica como possibilidade metodológica à pesquisa em educação. Trata-se de uma reflexão teórica sobre o horizonte hermenêutico como um princípio científico e educativo para a interlocução e para a contradição formativa em diálogo com o outro, superando as fraquezas e limitações da incompreensão. Os resultados da pesquisa apontam que a abordagem hermenêutica mostra-se muito importante para as pesquisas acadêmicas em educação, constituindo-se em uma rica fonte de análise, trazendo contribuições para a construção do problema de pesquisa, a análise de dados e sua respectiva interpretação, sendo fundamental para o jogo pergunta-resposta e para a abertura dialógica - via de acesso à compreensão humana.
\end{abstract}

PALAVRAS-CHAVE: Hermenêutica. Educação. Metodologia da pesquisa.

RESUMEN: El propósito de este trabajo es discutir y señalar caminos para el uso de la hermenéutica como una posibilidad metodológica a la investigación en educación. Se trata de una reflexión teórica sobre el horizonte hermenéutico como un principio científico y educativo para el diálogo y para la contradicción formativa en el diálogo con el otro, la superación de las debilidades y limitaciones de la incomprensión. Los resultados del estudio indican que el enfoque hermenéutico, por tanto, es muy importante para la investigación académica en la educación, convirtiéndose así en una rica fuente de análisis, con lo que las contribuciones a la construcción del problema de investigación, análisis de datos y su interpretación de los mismos, es fundamental para el juego de preguntas y respuestas y la apertura dialógica, a través del acceso a la comprensión humana.

PALABRAS CLAVE: Hermenéutica. Educación. Metodología de la investigación.

\footnotetext{
${ }^{1}$ Centro Universitário La Salle (UNILASALLE), Canoas - RS - Brasil. Doutoranda do Programa de PósGraduação em Educação. Integrante do grupo de pesquisa NETE/CNPq e bolsista da Capes. E-mail: pilarsidi@via-rs.net.

${ }^{2}$ Centro Universitário La Salle (UNILASALLE), Canoas - RS - Brasil. Professora Doutora do Programa de Pós-Graduação em Educação. Líder do Núcleo de Pesquisas sobre Tecnologias na Educação NETE/CNPq. E-mail: elaine.conte@unilasalle.edu.br.
}

RIAEE - Revista Ibero-Americana de Estudos em Educação, Araraquara, v.12, n.4 ,p. 1942-1954, out./dez. 2017. 
ABSTRACT: The aim of this text is to problematize and point out ways to use hermeneutics as a methodological possibility for research in education. It is a theoretical reflection on the hermeneutical horizon as a scientific and educational principle for dialogue and for the formative contradiction in dialogue with the other, overcoming the weaknesses and limitations of incomprehension. The results of the research indicate that the hermeneutic approach is very important for academic research in education, constituting a rich source of analysis, contributing to the construction of the research problem, data analysis and its respective interpretation, Being fundamental for the question-answer game and for the dialogical opening - a way of access to human understanding.

KEYWORDS: Hermeneutics. Education. Research methodology.

\section{Introdução}

O objetivo central deste trabalho é apresentar e problematizar, do ponto de vista filosófico e pedagógico, como a perspectiva hermenêutica colabora com as pesquisas na área da educação, impulsionando e aprimorando a arte de ensinar a compreensão, que sugere um esforço investigativo para acender ao conhecimento e então proceder à sua (auto)crítica. Para o debate envolvendo as questões hermenêuticas à pesquisa em educação, este artigo estrutura-se da seguinte maneira: inicialmente, caracteriza-se a hermenêutica e explicitam-se as condições de possibilidade metodológicas da atitude hermenêutica para a pesquisa em educação; em seguida, são trazidos os resultados de uma recontextualização hermenêutica tendo em vista os projetos de pesquisa e, por fim, encaminhamos uma discussão em torno da compreensão hermenêutica como um dos modos fundadores da pesquisa no horizonte aberto e dialógico da educação.

Vale enfatizar que ao voltarmos nosso olhar para a palavra hermenêutica, encontramos diversos significados, que são ilustrados e definidos historicamente, e vão desde a arte de interpretar os livros sagrados, os textos antigos, os sinais e os símbolos da cultura. Na verdade, a hermenêutica reconfigura a interdependência linguística, que reconhece a voz do outro e implica reconstrução aberta à interpretação contextualizada, privilegiando os discursos dos sujeitos, de onde brotam novos sentidos expressivos à apropriação dos estudos históricos. Daí que o discurso hermenêutico é tomado como condição para pensar a realidade, para que os preconceitos sejam revistos e reconstruídos nos contextos de atuação, sendo um dos aspectos indispensáveis ao processo científico e pedagógico, pois estimula o enfrentamento e a disposição crítica 
para a abertura ao diálogo com as diferenças e os diferentes mundos, como algo transformador de si e do outro (CRUZ, 2010).

Tendo como referência principal a obra Verdade e Método, de Hans-Georg Gadamer (1900-2002), buscamos estabelecer relações da abordagem hermenêutica como possibilidade metodológica à pesquisa em educação, lembrando que todas as produções humanas podem ser consideradas como textos. A problemática que conduz a pesquisa é a seguinte: é possível que a hermenêutica seja utilizada como um método de pesquisa na educação? Assim, no próximo tópico desvendamos a argumentação que habita a temporalidade e os contextos culturais da contemporaneidade, juntamente com o processo de busca de possíveis respostas para esta questão.

\title{
A Hermenêutica e a construção do projeto de pesquisa
}

No sentido da formulação de uma teoria da interpretação, os filósofos Friedrich Daniel Ernst Scheiermacher e Wilhelm Dilthey expandem o alcance de uma compreensão de base teológica e jurídica para o conceito de uma compreensão objetiva ${ }^{3}$ de qualquer tipo de texto e manifestação linguística.

\begin{abstract}
A hermenêutica, pode-se dizer, mostra os limites da dialética; esta, porém, mostra a possibilidade daquela. Justamente porque o universal sempre é pensado dentro das possibilidades de uma dada linguagem, a hermenêutica é essencial para a compreensão do pensamento, mesmo daquele que se perfaz no plano ideal-formal. O pensamento puro, não obstante ser caracterizado pela imutabilidade e universalidade, nunca se dá por si, mas sempre através de uma linguagem histórica, o que coloca a hermenêutica e a dialética em uma relação de interdependência também com a gramática, na medida em que na base está a operação de entendimento e comunicação linguística (SCHLEIERMACHER, 1999, p. 14).
\end{abstract}

Por tudo isso, falar em hermenêutica implica compreender, constituindo um ato infindável de reconciliação com o outro, com a natureza, com a realidade e com o mundo da vida. Palmer (2006) define hermenêutica como a ciência da compreensão, que desvela as estruturas existenciais que envolvem a ação humana, no sentido de desocultar o que parece familiar, questionando e trazendo os desdobramentos de uma tradução, que envolve riscos e a diversidade de expressões vitais. Para ele,

\footnotetext{
${ }^{3} \mathrm{~A}$ atitude hermenêutica é anterior à lógica indutiva, que buscava encontrar a regularidade, legalidade e uniformidade nos fenômenos humanos, tentando reduzir o sujeito de relações, de comportamentos e processos sociais ao que mensura a realidade (GADAMER, 2005).
}

RIAEE - Revista Ibero-Americana de Estudos em Educação, Araraquara, v.12, n.4 , p. 1942-1954, out./dez. 2017. 
tal concepção de hermenêutica implica uma crítica radical do ponto de vista da filologia, pois procura ultrapassar o conceito de hermenêutica como conjunto de regras, fazendo uma hermenêutica sistematicamente coerente, uma ciência que descreve as condições da compreensão, em qualquer diálogo. O resultado não é uma hermenêutica filológica, mas uma hermenêutica geral cujos princípios possam servir de base a todos os tipos de interpretação de texto (PALMER, 2006, p. 50).

A hermenêutica pode ser compreendida como a maneira pela qual interpretamos algo no movimento que interessa e constitui o ser humano, de formar-se e educar-se. A interpretação decorre de um texto, um gesto, uma atitude, uma palavra de abertura e relação com o outro, que é capaz de se comunicar, de interagir. A hermenêutica busca uma reflexão e uma compreensão sobre aquilo que vemos, lemos, vivenciamos, criando uma cultura imersa em diferentes tradições e experiências. Implica também na forma como realizamos o movimento para nos (re)conhecer a partir das experiências no mundo, ou seja, na medida em que interpretamos algo, relacionamos diretamente com a visão de mundo que temos, advindas de nossas experiências anteriores. Sendo assim, tematizar a compreensão como modo fundador da existência humana lança questões críticas sobre o que é educar, aprender, compreender, pesquisar e dialogar, para dar conta da singularidade da vida humana.

Quando a experiência hermenêutica enseja outras possibilidades interpretativas, a educação como se desprende das amarras conceituais provenientes da visão científico-objetivista e da tradição metafísica, passa então a produzir os efeitos benéficos da abertura de horizontes e da ampliação da base epistemológica. Assim, a possibilidade compreensiva da hermenêutica desfaz o prejudicial equívoco que há entre educação compensatória e educação no sentido amplo da formação (HERMANN, 2003, p. 9-10).

Para Gadamer (2005, p. 407), "nossas reflexões sempre nos levaram a admitir que, na compreensão, sempre ocorre algo como uma aplicação do texto a ser compreendido à situação atual do intérprete". Afinal de contas, não há compreensão humana que não seja mediatizada por signos, símbolos e textos. Por isso, para que a compreensão ocorra é preciso que aquilo que tentamos interpretar faça sentido para nós mesmos. O autor propõe como o problema da hermenêutica o tripé: interpretaçãocompreensão-aplicação, sendo que a aplicabilidade "é um momento tão essencial e integrante do processo como a compreensão e a interpretação" (GADAMER, 2005, p. 407). Na perspectiva de Gadamer (2005, p. 29), 
[...] o fenômeno da compreensão e a maneira correta de se interpretar o compreendido não são apenas um problema específico da teoria aplicado às ciências do espírito. Desde os tempos mais antigos, sempre houve uma hermenêutica teológica e outra jurídica, cujo caráter não era teórico-científico, mas correspondia e servia muito mais ao procedimento prático do juiz ou do sacerdote instruídos pela ciência.

Assim, a hermenêutica relaciona-se diretamente com interpretação e com a compreensão dos fenômenos, das atitudes e dos comportamentos humanos, dos textos e das palavras. Segundo Gadamer (2005, p. 407), "atualmente a hermenêutica é a teoria metodológica da investigação das ciências do espírito". O que há de verdadeiramente comum e consensual a todas as formas de hermenêutica, é que "o sentido que se deve compreender somente se concretiza e se completa na interpretação" (GADAMER, 2005, p. 436).

Todo projeto de pesquisa constitui-se de uma interrogação, que se denomina de problema de pesquisa, com os objetivos, que são as possíveis respostas a estas perguntas, a justificativa, que consiste na necessidade sentida e na motivação que levou o pesquisador a seguir aquela temática, tendo em vista a contribuição para a sociedade e para o avanço das pesquisas na área. Além da metodologia, que é o caminho a ser percorrido (o que efetivamente fez e o como fez) e do referencial teórico, que será a etapa onde o pesquisador indicará os autores que pretende se apropriar, com suas respectivas teorias para dar conta da estrutura da pesquisa. Nas palavras de Alves (1991, p. 56):

[...] um projeto de pesquisa consiste basicamente na formulação clara da questão (ou questões) que se pretende investigar e na descrição da maneira pela qual se planeja respondê-la, acompanhadas de uma argumentação que destaque a relevância do estudo e a adequação da estratégia proposta. Em outras palavras, seja qual for o tipo de pesquisa, o projeto deverá indicar: (a) o que se pretende investigar (o problema elou questões do estudo); (b) como se planejou conduzir a investigação de modo a responder às questões propostas (procedimentos metodológicos); e (c) porque o estudo é relevante (em termos de contribuições teóricas e práticas que o estudo pode oferecer).

Esse giro investigativo não funciona sem o componente da resistência, sem o contraditório, ou aquilo que o nega (diferença). Daí que surge o estranhamento hermenêutico e a necessidade de mudar, de ultrapassar os obstáculos conservadores para compreender o pensamento da humanidade na conversação, pois o visível tem sempre aspectos de invisibilidade.

RIAEE - Revista Ibero-Americana de Estudos em Educação, Araraquara, v.12, n.4 , p. 1942-1954, out./dez. 2017 
Podemos dizer que determinadas informações sobre o estudo proposto podem, e devem, ser antecipadas, tanto para orientação do próprio pesquisador com o para fins da avaliação da proposta. Tais informações compreendem: a focalização do problema (incluindo-se aí as questões do estudo, o quadro teórico e a unidade de análise) e sua relevância, e os procedimentos metodológicos (ALVES, 1991, p. 57).

Curiosamente, as contribuições que a hermenêutica pode trazer para a elaboração do projeto de pesquisa iniciam desde a escolha do tema perpassando pela formulação do problema, ou das questões e reflexões de partida. Para Gadamer (2005, p. 484), "a lógica de pergunta e resposta deve reconstruir duas perguntas distintas que encontrarão também duas respostas distintas: a pergunta pelo sentido no curso de um grande acontecimento, e a pergunta para ver se este curso se deu de acordo com o plano". E o filósofo acrescenta: "compreender uma pergunta significa colocar essa pergunta. Compreender uma opinião significa compreendê-la como resposta a uma pergunta" (GADAMER, 2005, p. 489). Assim tem-se que a formulação do problema de pesquisa deriva de uma abordagem hermenêutica no sentido de ir além do diagnóstico, jogando luzes ao problema. O mesmo pode ocorrer com a metodologia? Discutimos isso no próximo tópico.

\section{A Hermenêutica e suas contribuições metodológicas}

A metodologia é o caminho que o pesquisador vai percorrer, abrangendo os métodos e técnicas utilizados para encontrar a melhor forma de ajudar a compreender e responder ao problema de pesquisa. A metodologia da pesquisa é de fundamental importância para a realização do projeto, como um projetar-se de provisoriedade e inteligibilidade de transformação, no abrir-se e lançar-se como um passo adiante, para renovação das problemáticas e das possibilidades de si e do mundo. Precisa estar descrita de forma clara tanto para quem lê o trabalho quanto para quem o realiza. Levando-se em conta que as investigações em educação, muitas vezes abrangem questões complexas e multifacetadas, que exigem uma imersão no campo a ser pesquisado com um contato direto com os participantes. Muitos estudiosos optam por realizar uma pesquisa de natureza qualitativa como forma de reconhecer a variedade de tradições e de estratégias para compreender a realidade. Para Alves (1991, p. 54),

[...] o que existe de mais comum entre suas diversas formas é a tradição verstehen (hermenêutica). Esta abordagem parte do pressuposto de que as pessoas agem em função de suas crenças,

RIAEE - Revista Ibero-Americana de Estudos em Educação, Araraquara, v.12, n.4 , p. 1942-1954, out./dez. 2017. 
percepções, sentimentos e valores e seu comportamento tem sempre um sentido, um significado que não se dá a conhecer de modo imediato, precisando ser desvelado.

Neste âmbito, a pesquisa qualitativa em educação pode ser vista como de abordagem eminentemente hermenêutica, pois utiliza o diálogo na construção e interpretação da cultura, como forma de educar e educar-se, sendo que a compreensão hermenêutica do processo de educar se realiza por meio da linguagem que pressupõe abertura ao outro. Segundo Minayo (1993, p. 24),

[...] a pesquisa qualitativa trabalha com o universo de significados que correspondem a um espaço mais profundo das relações que não podem ser reduzidos a equações. Compreende e explica a dinâmica das relações sociais, que, por sua vez, são depositárias de crenças, valores, atitudes e hábitos. Trabalha com a vivência e também com a compreensão das estruturas como resultado da ação humana.

Só através do diálogo é possível aprender de forma evolutiva, incorporando os dados históricos de pesquisas realizadas, para compreender o contexto estudado e as atitudes dos participantes, garantindo a fusão de horizontes de interpretação como elemento de acesso ao mundo e abertura para a conversação e o aprender transformador. De acordo com Gadamer (2005, p. 489),

[...] todo compreender é sempre algo mais que a mera compreensão. Nós partimos do conhecimento também de que a compreensão que se exerce nas ciências do espírito é essencialmente histórica, isto é, que também nelas, um texto só pode ser compreendido se em cada caso for compreendido de uma maneira diferente.

Neste sentido, é importante salientar que na pesquisa qualitativa, o investigador precisa, muitas vezes, emergir na cultura que irá pesquisar, observando atentamente tudo que ocorre no campo pesquisado, de onde decorre seu caráter interpretativo, que confere intencionalidade à ação e ao ato de (re)conhecer. A vida implica um ato de compreensão histórica e a busca de sentido hermenêutico implica aventurar-se pelas atitudes das pessoas envolvidas, por meio de crenças, ideias do grupo investigado, compartilhamentos de emoções e sensibilidades, tudo deve ser visto como de suma importância para o pesquisador.

Partindo destes pressupostos, não se pode, no processo de investigação, deixar de valorizar a imersão do pesquisador no contexto, em interação com os participantes, procurando apreender o significado por eles atribuído aos fenômenos estudados. É também compreensível que o foco do estudo vá sendo progressivamente

RIAEE - Revista Ibero-Americana de Estudos em Educação, Araraquara, v.12, n.4 , p. 1942-1954, out./dez. 2017. 
ajustado durante a investigação e que os dados dela resultantes sejam predominantemente descritivos e expressos através de palavras (ALVES, 1991, p. 55).

As possibilidades compreensivas e de dizer o próprio mundo estão relacionadas à abordagem hermenêutica, que rompe qualquer pretensão de rigidez e domínio de todo conhecimento, ou de ter a última palavra, diria Gadamer (2005), uma vez que contribui para o crescimento e a possibilidade infinita de construção mútua e interdependente de outros saberes. A dialogicidade compreensiva tem uma dupla dimensão, no "sentido de ida e volta [que] permite verificar os processos mutuamente e constatar erros no percurso" (GAMBOA, 2013, p. 61). A metodologia qualitativa, muitas vezes, faz uso de entrevistas como técnica de pesquisa. Para ilustrar isso, trataremos dessa conversação livre (de abertura para o aprender) e intencional (dando sentido à investigação), como possibilidade interpretativa posta em jogo no tópico a seguir.

\section{A interpretação dos dados}

A interpretação dos dados, olhando concretamente para o que foi relacionado discursivamente, implica um momento de revisão final do trabalho, de reconsiderar as bases hermenêuticas da pesquisa. Por isso, ler um texto hermeneuticamente, conforme Gadamer (2005), é considerar a experiência de choque (ou estranhamento) que ele nos causa, percebendo as diferenças no uso da linguagem e localizando-as historicamente, de modo que os preconceitos sejam vistos, desconstruídos e/ou reconfigurados em um outro contexto. No caso deste horizonte metodológico, o pesquisador deve se perguntar em que sentido as teorias e ações pedagógicas foram (des/re)contextualizadas. A estrutura das entrevistas, especialmente das entrevistas abertas, baseia-se na dialética entre pergunta e resposta, e entre entrevistado x entrevistador. Para Minayo (1992, p. 28), a entrevista "não significa uma conversa despretensiosa e neutra, uma vez que se insere como meio de coleta dos fatos relatados pelos atores, enquanto sujeitos-objeto da realidade que vivenciam uma determinada realidade que está sendo focalizada".

As entrevistas são muito mais do que meros relatos, através delas podemos compreender com uma maior amplitude o contexto do fenômeno estudado, bem como (re)conhecer o mundo em que o entrevistado habita. A hermenêutica contribui bastante na exploração dos conceitos e na interpretação das palavras proferidas pelo entrevistado, garantindo a contextualização e a historicidade para a formulação de novas questões e problemas de pesquisa. Neste aspecto, 
[...] quando tentamos considerar o fenômeno hermenêutico guiados pelo modelo da conversação que se dá entre duas pessoas, o caráter comum que serve de orientação entre essas duas situações aparentemente tão diversas, entre a compreensão do texto e o acordo numa conversação, consiste sobretudo no fato de que toda compreensão e todo acordo têm em mira alguma coisa com a qual estamos confrontados. Da mesma forma que nos pomos de acordo com o nosso interlocutor sobre algum assunto, também o intérprete compreende a coisa que lhe diz o texto. Essa compreensão da coisa ocorre necessariamente na formulação da linguagem, mas não no sentido de que uma compreensão se dá justamente nesse vir-à-fala da própria coisa em pauta. Assim, seguimos imediatamente a estrutura da verdadeira conversação, para assim destacar a peculiaridade daquela outra conversação representada pela compreensão de textos. Enquanto acima, seguindo a essência do diálogo, destacamos o significado constitutivo da pergunta para o fenômeno hermenêutico, será de utilidade demonstrar agora o caráter de linguagem presente no diálogo como um momento hermenêutico e que esse caráter de linguagem forma a base de todo perguntar (GADAMER, 2005, p. 493).

Deste modo, depreende-se que a hermenêutica é essencial para o entendimento e compreensão do entrevistador, sendo que quando falamos em pesquisa acadêmica, não podemos deixar de lembrar também que além do investigador estabelecer um diálogo com o sujeito da investigação, efetuar a entrevista, compreender e interpretar o que está sendo dito, ele ainda terá a tarefa de reconstruir e integrar esta compreensão no movimento discursivo da atualidade. Com essa renovação e revisão dos discursos, o autor da pesquisa consegue estabelecer novamente um diálogo aberto com outros textos e interpretações de mundo.

A partir de uma abordagem hermenêutica poderíamos dizer que o texto é a mensagem, a fala, o discurso dos sujeitos; o contexto do texto passa a ser o contexto social-político-econômico-cultural-vital dos sujeitos que fazem a experiência do processo educativo, como uma formação crítica ou como alienação. O universo das significações se dá num contexto concreto, mas como captar o discurso (enquanto modo de dizer e interpretar o mundo) do ser-aí? (GHEDIN, 2004, p. $5)$.

A fase de interpretação de dados é a última prevista para a consolidação e validação da pesquisa acadêmica, pois é no processo de produção desse conhecimento que os conceitos e formas de compreensão relevantes são extraídos e usados para revelar o quanto a pesquisa contribuiu socialmente para a resolução dos problemas e objetivos propostos, pensando no potencial formativo que a recontextualização do conhecimento gerou. No caso da pesquisa de bases hermenêuticas é muito interessante garantir as formas de tratamento discursivo, análise e interpretação de dados, ou seja, é

RIAEE - Revista Ibero-Americana de Estudos em Educação, Araraquara, v.12, n.4 , p. 1942-1954, out./dez. 2017. 
fundamental que se tenha em mãos as gravações e transcrições das entrevistas para depois interpretá-las, tendo em vista as múltiplas relações envolvidas nos fenômenos sociais. Em outras palavras, cabe observar que:

[...] a transcrição tendo por fim uma análise da enunciação deve conservar o máximo de informação tanto linguística (registro da tonalidade dos significantes) como paralinguística (anotações dos silêncios, onomatopeias, perturbações de palavra e de aspectos emocionais tais como o riso, o tom irônico, etc.) (BARDIN, 2000, p.174).

Teoricamente, nas leituras e compreensões discursivas tudo favorece e faz parte da interpretação humana, os gestos, as mudanças no tom de voz, os soluços, as pausas, as emoções que cada entrevistado expressa no momento da fala, assim como o teor do que está sendo dito. O discurso é linguagem e leitura do mundo, porque pela expressão, seja através da entonação da palavra, do gesto ou do corpo, se dá abertura e se articula as significações de um mundo interdependente da compreensão humana em obra, em projeto. É com esse olhar constitutivo da existência aberta e em desenvolvimento, que as falas devem ser tomadas no processo amplo de investigação e análise discursiva. Este processo é sempre uma negociação entre entrevistador e entrevistado, sendo que ambos devem estar abertos ao diálogo. Segundo Gadamer (2005, p. 499):

[...] a conversação é um processo do acordo. Toda verdadeira conversação implica nossa reação frente ao outro, implica deixar realmente espaço para seus pontos de vista e colocar-se no seu lugar, não no sentido de querer compreendê-lo como essa individualidade, mas compreender aquilo que ele diz.

Deste modo, o que está em jogo é o significado da fala e sua respectiva interpretação e compreensão por parte do pesquisador daquilo que está sendo dito, relatado e mencionado pelo entrevistado. A hermenêutica é de suma importância para todo este processo de análise de dados e dos textos, que colaboram para a elucidação do que está sendo proferido em determinado contexto. Na verdade, toda a compreensão de mundo traz consigo a experiência humana e a interpretação, que coloca em movimento toda estrutura prévia do compreendido. Por isso, segundo Gadamer (2005, p. 478), "ser que pode ser compreendido é linguagem", visto que só compreendemos algo quando fazemos parte do contexto compreendido. $\mathrm{O}$ círculo hermenêutico significa que não se pode conceber a compreensão fora de um contexto histórico e social. A circularidade da compreensão constitui-se a partir da relação e da condição de ser capaz de comunicar o

RIAEE - Revista Ibero-Americana de Estudos em Educação, Araraquara, v.12, n.4 , p. 1942-1954, out./dez. 2017. 
seu conhecimento, de partilhá-lo, integrando a dialética intersubjetiva, que exige reciprocidade e intercomunicação. Compreender equivaleria então a ver e comunicar melhor, remete à interdependência constitutiva do todo e das partes e à impossibilidade da compreensão por dedução. Contudo,

A possibilidade compreensiva da hermenêutica permite que a educação torne esclarecida para si mesma suas próprias bases de justificação, por meio do debate a respeito das racionalidades que atuam no fazer pedagógico. Assim, a educação pode interpretar o seu próprio modo de ser, em suas múltiplas diferenças (HERMANN, 2003, p. 83).

Segundo Weller (2007), a hermenêutica da segunda metade do século XX desempenhou e desempenha ainda um importante papel no desenvolvimento de metodologias e métodos de análise qualitativa de dados empíricos na educação, tendo relevância também para a (re)construção de novos sentidos investigativos.

\section{Considerações finais}

Procuramos argumentar que a produtividade da hermenêutica como uma abordagem metodológica à pesquisa em educação implica a incorporação de uma leitura discursiva e necessariamente crítica e compreensiva da realidade, mas que não está imune aos impasses e conflitos das interpretações sedimentadas. Após a realização desta reflexão, chegou-se à conclusão de que todas as pesquisas educacionais apresentam a utilização da abordagem hermenêutica em alguma de suas fases, ou em muitas delas, para entender os discursos e os jogos de linguagem atinentes às questões da historicidade humana. Seja na fase da construção do problema de pesquisa, na interpretação de dados, na construção do referencial teórico ou em virtude das articulações contextuais, a hermenêutica está inserida. No caso da pesquisa qualitativa, juntamente com as técnicas da aplicação de entrevistas, a hermenêutica apresenta contribuições significativas, na formulação das questões a serem indagadas, nas interpretações das falas dos informantes, na compreensão destas falas à luz das demandas sociais e dos referenciais teóricos identificados.

O próprio horizonte hermenêutico pode ser vislumbrado como uma historicidade não-linear porque dá abertura à renovação constante, a um projetar-se que se aloja na conversação, na difusa fronteira do ilimitado. A hermenêutica enquanto atitude de pesquisa e metodologia no campo da educação oferece valiosos recursos para a

RIAEE - Revista Ibero-Americana de Estudos em Educação, Araraquara, v.12, n.4 , p. 1942-1954, out./dez. 2017. 
interpretação textual e discursiva, bem como amplia e aprofunda visões de mundo, tendo como foco os contextos de interação que se quer (re)conhecer na realidade vital. Tal compreensão hermenêutica serve para investigar a natureza, as finalidades e os processos necessários à práxis educativa, intencionando propor a realização desses processos nos vários contextos em que as práticas ocorrem. Afinal de contas, a educação é um projeto político-pedagógico-social que sustenta as ações e decisões culturais, que busca uma ampliação da visão de mundo, uma utopia pedagógica, tendo o futuro como possibilidade hermenêutica de cada lócus pesquisado.

\section{REFERÊNCIAS}

ALVES, A. J. O planejamento de pesquisas qualitativas em educação. Cadernos de Pesquisa, n. 77, p. 53-61, 1991.

BARDIN, L. Análise de conteúdo. Edições 70: Lisboa, 2000.

CRUZ, R. J. B. Hermenêutica e educação: o sentido gadameriano de diálogo ressignificando as relações pedagógicas. Revista Espaço Acadêmico, v. 10, n. 112, p. 43-50, 2010.

DILTHEY, W. A compreensão dos outros e das suas manifestações de vida. In: GARDINER, P. (Org.). Teorias da história. Lisboa: Fundação Calouste Gulbenkian, 1984.

GADAMER, H. G. Verdade e método I. Traços fundamentais de uma hermenêutica filosófica. São Paulo: Editora Universitária São Francisco, 2005.

GAMBOA, S. S. Projetos de pesquisa, fundamentos lógicos: a dialética entre perguntas e respostas. Chapecó: Argos, 2013.

GHEDIN, E. Hermenêutica e pesquisa em educação: caminhos da investigação interpretativa. In: SEMINÁRIO INTERNACIONAL DE PESQUISA E ESTUDOS QUALITATIVOS - SIPEQ, 2. ed., 2004. Anais II Seminário internacional de pesquisa e estudos qualitativos, Universidade Sagrado Coração: Bauru, São Paulo. p. 1-14.

HERMANN, N. Hermenêutica e educação. Rio de Janeiro: DP\&A, 2003.

MINAYO, M. C. S. Pesquisa social. Teoria método e criatividade. São Paulo: Vozes, 1992.

MINAYO, M. C. S. O desafio do conhecimento. São Paulo: Editora Hucitec, 1993.

PALMER, R. E. Hermenêutica. Tradução Maria Luísa Ribeiro Ferreira. Lisboa: Edições 70, 2006. 
SCHLEIERMACHER, F. D. E. Hermenêutica - Arte e técnica da interpretação. Trad. Celso Reni Braida. Rio de Janeiro: Vozes, 1999.

WELLER, W. A hermenêutica como método empírico de investigação. In: REUNIÃO ANUAL DA ANPED, 30 ed. Anais 30 Reunião Anual da ANPED, Caxambu: UFMG, Minas Gerais. p. 7-10.

\section{Como referenciar este artigo}

SIDI, Pilar de Moraes.; CONTE, Elaine. A hermenêutica como possibilidade metodológica à pesquisa em educação. Revista Ibero-Americana de Estudos em Educação, Araraquara, v. 12, n. 4, p. 1942-1954, out./dez. 2017. Disponível em: <http://dx.doi.org/10.21723/riaee.v12.n4.out./dez.2017.9270>. E-ISSN: 1982-5587.

Data de Submissão: 21/01/2017

Aprovado em: 30/10/2017 